\title{
Familiar and Unfamiliar Face Recognition in a Crowd
}

\author{
Hiroshi Ito1, Aki Sakurai2 \\ ${ }^{1}$ Department of Psychology, Aichi University, Toyohashi, Japan \\ ${ }^{2}$ Chubu Telecommunications Co., Nagoya, Japan \\ Email: ep91itohiroshi@yahoo.co.jp
}

Received 28 April 2014; revised 26 May 2014; accepted 21 June 2014

Copyright (C) 2014 by authors and Scientific Research Publishing Inc.

This work is licensed under the Creative Commons Attribution International License (CC BY). http://creativecommons.org/licenses/by/4.0/

(c) (i) Open Access

\section{Abstract}

The purpose of the present study was to investigate whether the visual search process for familiar faces differs from that for unfamiliar faces. We used a single-target visual search task and recorded eye movements of participants during the task. We employed three different types of face familiarity: personally familiar faces (friends and teachers), famous faces, and unfamiliar faces. Participants had to search through arrays of faces for a target face. In each trial, a target face and three distractor faces were horizontally aligned and presented at the same time. In the personally familiar or famous condition, the target was a personally familiar face or a famous face, respectively, and the distractor faces were unfamiliar. In the unfamiliar condition, the target was an unfamiliar face and the distractor faces were personally familiar. The reaction times to identify the target demonstrated that the visual search for unfamiliar faces is slower than that for personally familiar faces and famous faces, but there was no significant difference between reaction times to recognize the personally familiar and the famous face targets. Additionally, the eye movement results in the unfamiliar face condition showed that an exhaustive search of the entire array occurred more frequently than a self-terminating search, but this was not true for both the personally familiar faces and famous faces conditions. These results suggest that the visual search process for familiar faces (personally familiar and famous) in a crowd differs from that for unfamiliar faces.

\section{Keywords}

Personally Familiar Face, Famous Face, Unfamiliar Face, Face Perception, Visual Search

\section{Introduction}

People recognize familiar faces in a crowd. There has been a continuing interest in how people recognize familiar and unfamiliar faces since the 1970s (Bruce, 1979; Ellis, Shepherd, \& Davies, 1979) to the present (Persike, 
Meinhardt-Injac, \& Meinhardt, 2013; Walton \& Hill, 2012). Many previous studies suggest that familiar and unfamiliar faces are processed in different ways (Balas, Cox, \& Conwell, 2007; Barton, Radcliffe, Cherkasova, Edelman, \& Intriligator, 2006; Clutterbuck \& Johnston, 2002; Gobbini, Leibenluft, Santiago, \& Haxby, 2004; Persike et al., 2013; Young, Hay, McWeeny, Flude, \& Ellis, 1985; see Johnston \& Edmonds, 2009; Natu \& O'Toole, 2011, for review). Both behavioral and neuroscience studies have provided evidence to support the differences in the processing of familiar and unfamiliar faces.

Johnston and Edmonds (2009) pointed out that the major differences between familiar and unfamiliar face processing have been observed in behavioral experiments. Participants can recognize familiar faces in poor viewing conditions, such as in low-quality images and at variable viewpoints (Balas et al., 2007; Burton, Bruce, \& Hancock, 1999; Johnston \& Edmonds, 2009; Natu \& O’Toole, 2011). Increased familiarity of a face results in increased accuracy of identification and facilitation of the recognition process under many kinds of incomplete recognition conditions. On the other hand, recognizing unfamiliar faces is easily disrupted in poor lighting conditions (Hill \& Bruce, 1996; Johnston, Hill, \& Carman, 1992), by changes in viewpoint (Balas et al., 2007; Bruce, 1982; Bruce et al., 1999; Hill, Schyns, \& Akamatsu, 1997; O’Toole, Edelman, \& Bulthoff, 1998), and when image or video quality is poor (Balase et al., 2007; O’Toole et al., 2010). It is also known that the internal features of a face (eyes, nose, and mouth area) are more important for the recognition of familiar faces than the external features (face shape and hair), although the recognition of unfamiliar faces is similarly efficient from internal or external features (Johnston \& Edmonds, 2009; O’Donnell \& Bruce, 2001; Young et al., 1985). For example, in an earlier study, Young et al. (1985) reported that familiar faces were matched faster when paired with internal rather than with external features, although unfamiliar face matches presented no such difference. Subsequent studies showed that unfamiliar faces were recognized more slowly and less accurately than familiar faces if the viewpoint was incongruent between the study phase and the test phase (Balas et al., 2007; Hill et al., 1997). The many advantages of familiar faces are probably derived from the differences in the neural mechanisms involved in the recognition of these faces.

Many neuropsychological studies have described patients who present various face recognition impairments, for example, prosopagnosia or other dissociations between performance of tasks that require the processing of familiar and unfamiliar faces (Malone, Morris, Kay, \& Levin, 1982; Tranel, Damasion, \& Damasio, 1988; Warrington \& James, 1967; Young, Newcombe, DeHaan, Small, \& Hay, 1993). For example, Young et al. (1993) described prosopagnosia patients who could identify familiar faces but were poor at identifying unfamiliar faces. These findings suggest that there are different neural mechanisms between recognition of familiar and unfamiliar faces.

Functional neuroimaging studies have detected some brain regions involved in unfamiliar face perception that respond more strongly to faces than to other objects (Natu \& O'Toole, 2011). This network of brain regions consists of the fusiform gyrus (Hoffman \& Haxby, 2000; Kanwisher, McDermott, \& Chun, 1997), the inferior occipital gyrus (Halgren et al., 1999), and the superior temporal sulcus (STS) (Allison, Puce, \& McCarthy, 2000; Haxby, Hoffman, \& Gobbini, 2000). These core face-selective brain areas include the representation of the invariant aspects of faces for face recognition in the fusiform and inferior occipital gyri, and the variant aspects of faces, such as expression, gaze, and facial speech, in the posterior STS (Haxby et al., 2000; Natu \& O'Toole, 2011). On the other hand, familiar faces activate not only the core face-selective regions, but also other brain regions that represent semantic, episodic, and emotional information about an individual (Ewbank \& Andrews, 2008; Gobbini et al., 2004; Gobbini \& Haxby, 2007; Gorno-Tempini \& Price, 2001; Rossion, Schiltz, \& Crommelinck, 2003; Sugiura et al., 2001). These richly interconnected representations could affect the ease of recognition of familiar faces.

Although it is widely acknowledged that there are differences between the processing of familiar and unfamiliar faces, little is known about the visual search process for a familiar face in a crowd of unfamiliar faces and vice versa. The aim of the present study was to examine whether the visual search process for familiar faces differs from that for unfamiliar faces. In order to assess this issue, we used a single-target visual search task (Becker, Anderson, Mortensen, Neufeld, \& Neel, 2011; Treisman \& Gelade, 1980; Thornton \& Gilden, 2007; Wolfe, 1992) and recorded eye movements of participants during the task by using an eye tracker. This task requires participants to search through arrays of objects for a target object and, therefore, can disclose differences in the efficiency with which particular target classes can be found (Becker et al., 2011). In the present study, we used only target-present trials, that is, targets were presented in every array. If a target is equally likely to be present in each possible location within an array, participants would not need to search the arrays exhaustively (an ex- 
haustive search), but would terminate the search when the target is found (a self-terminating search).

We were also interested in investigating the effect of different types of face familiarity: personally familiar faces (e.g., close relatives and friends) known through real-world experiences, and famous faces (e.g., celebrities and politicians) whom the participants knew through the media. Previous studies suggested that personal familiarity of faces differs from famous face familiarity in terms of the amount of exposure, knowledge about personal traits, and emotional and semantic associations (Gobbini et al., 2004; Natu \& O’Toole, 2011). Thus, personal familiarity is associated with not only the visual information of a face, but also with emotional and social information, such as the person's mental state, personality, and the emotions that people experience upon seeing the face (Gobbini \& Haxby, 2007).

\section{Method}

\subsection{Participants}

Twelve undergraduate students ( 3 males and 9 females; age range: 21 to 23 years) participated in the present experiment. All participants had normal or corrected-to-normal vision and were naive with respect to the hypotheses under investigation. They gave written informed consent according to the recommendations of the Declaration of Helsinki to participate in the experiment. This study was approved by the local ethics committee.

\subsection{Design}

The experiment employed a one-factor (level of face familiarity: personally familiar face, famous face, or unfamiliar face) within-subject design.

\subsection{Stimuli}

We used gray-scale photographs of faces with a high-resolution frontal view so that broad color cues could not facilitate recognition of targets. Figure 1 illustrates examples of the images used in this experiment. We rejected images with excess jewelry, make-up, open mouths, or glasses. The images were $224 \times 192$ pixels in size. Each face was isolated from the original photographs and superimposed on a gray background using image editing software (Photoshop CS6; Adobe, California, USA). We employed three different familiarities of faces: personally familiar faces (friends and teachers in the same department of psychology), famous faces (actors, singers, public leaders, athletes), and unfamiliar faces (anonymous individuals).

For personally familiar faces, participants in this experiment were shown the entire set of 70 individuals (28 males and 42 females) who are undergraduate students or faculty in the Department of Psychology at Aichi University, and were asked to select 32 individuals familiar to them a month before the experiment. Eight of the selected individuals were randomly assigned to be target stimuli in the personally familiar condition, and the remaining 24 of them were assigned to be distractor stimuli in the unfamiliar condition. The participants rated these faces for familiarity on a 10-point scale, with 0 being not familiar at all and 10 being extremely familiar to them. The average familiarity rating for all personally familiar faces was 8.1 (SD 1.2). For famous faces, we selected eight images from the internet ( 4 males and 4 females). The eight famous faces were only assigned to be

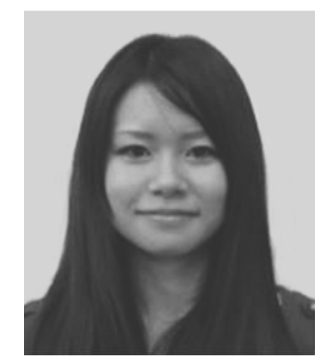

(a)

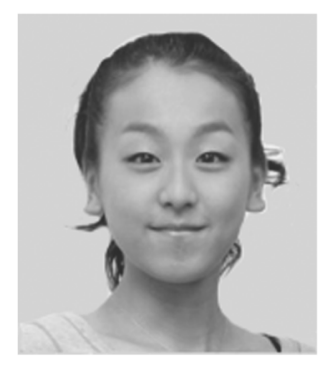

(b)

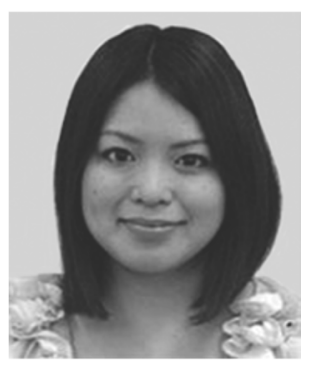

(c)

Figure 1. Examples of stimuli used in the present study. (a) Personally familiar faces; (b) Famous faces; (c) Unfamiliar faces. 
target stimuli in the famous condition and were not assigned to be distractor stimuli in any other conditions. All the famous faces were well known to the participants. The participants rated these faces for familiarity on a 10point scale in the same manner as the personally familiar faces. The average familiarity rating for all famous faces was 8.7 (SD 0.8). For unfamiliar faces, we used 56 individuals who were selected from the pool of photographs of students and faculty in other university (28 males and 28 females). Eight of the selected individuals were randomly assigned to be target stimuli in the unfamiliar condition, and the remaining 48 of them were assigned to be distractor stimuli. The half of the distractor stimuli (24 individuals) was used in the personally familiar condition, and the remaining half of them (24 individuals) was used in the famous condition. These unfamiliar faces were selected to match personally familiar and famous faces on age, race, and gender. In total we presented participants with 24 target stimuli ( 8 targets $\times 3$ conditions) and 72 distractor stimuli ( 24 distractors $\times$ 3 conditions). None of the target and distractor stimuli were used more than once in each participant.

In the visual search task in the present study, a target face (personally familiar, famous, or unfamiliar) and three distractor faces were horizontally aligned and presented at the same time. In the personally familiar or famous condition, the target face was a personally familiar face or a famous face, respectively, and the distractor faces were unfamiliar faces. Conversely, in the unfamiliar condition, the target face was an unfamiliar face and the distractor faces were personally familiar faces. None of the target stimuli were used more than once in each condition.

\subsection{Apparatus}

The stimuli were displayed on a 17-inch CRT color monitor (EDT17AD, EPSON, Suwa, Japan) with a screen resolution of $1280 \times 1024$ pixels and a refresh rate of $75 \mathrm{~Hz}$. This monitor was located at a distance of approximately $50 \mathrm{~cm}$ away from the participant. The mean luminance of the screen was $75 \mathrm{~cd} / \mathrm{m}^{2}$. Eye movements were recorded using an eye tracker (EMR-AT VOXER, NAC Image Technology Inc., Tokyo, Japan) with a sampling rate of $60 \mathrm{~Hz}$. We used EMR-dFactory version 1.1, eye movement data analysis software (NAC Image Technology Inc., Tokyo Japan). The eye tracker was calibrated to each participant's dominant eye, but viewing was binocular. Calibration was done using a nine-point calibration accuracy test. A chin rest maintained the participants' viewing position and distance.

\subsection{Procedure}

The participants were tested individually in a dimly lit room. The room was darkened so that the ambient illumination approximately matched the illumination on the screen. They were comfortably seated and performed the visual search task. In this task, they were asked to indicate a target face in a crowd of three distractor faces. They were encouraged to respond as quickly and accurately as possible. We recorded their eye movements during the task.

Each trial was begun by presenting a black fixation point displayed at the center of the monitor on a white background for one second, followed by a blank interval of 0.5 seconds. Then, a target face and three distractor faces were presented until the participant responded. These four faces were horizontally aligned and presented at the same time. The centers of the rightmost and leftmost face images were about $12 \mathrm{~cm}$ (442 pixels) away from the center of the screen, and the centers of the two face images at the middle of the face array were about $4 \mathrm{~cm}$ (147 pixels) away from the center of the screen. The task of the participants was to look for an instructed target face (personally familiar face, famous face, or unfamiliar face). They were asked to press the " 1 " key with the left middle finger when the target face was presented at the leftmost position, to press the "2" key with the left index finger when it was presented at the second position from the left, to press the " 3 " key with the right index finger when it was presented at the second position from the right, and to press the " 4 " key with the right middle finger when it was presented at the rightmost position. After responding, participants were given an intertrial interval of five seconds. Participants were not given feedback on whether their response was correct or not.

Prior to participating in the experimental trials, each participant completed a block of 6 practice trials using the experimenters' faces. The experimental session consisted of three blocks (the personally familiar face condition, the famous face condition, and the unfamiliar face condition). The order of the three experimental blocks was counterbalanced across participants, and each block consisted of eight trials. In total we presented each participant with 24 trials consisting in three blocks of eight trials. The target faces were presented once in one of the four positions in each block. The number of presented target faces was balanced across the four positions. The 
order of the eight trials in each condition was randomized across participants. After each experimental block there was a two-minute rest period. The experimental session lasted for approximately ten minutes.

After the visual search task, all participants took part in a familiarity verification exercise. They were shown printed copies of all the unfamiliar faces and asked to provide any copies of the unfamiliar faces if they had seen these individuals before. As a result, none of the participants had ever seen these individuals before.

\section{Results}

\subsection{Accuracy}

The average performance of correct responses for all participants across all three conditions exceeded 99\% (personally familiar: 99\%; famous: 99\%; unfamiliar: 100\%). In order to assess whether the familiarity of faces affects the visual search accuracy of a target face in a crowd of distractors, the proportion of correct responses was entered into a one-way repeated-measures ANOVA with the level of face familiarity (personally familiar, famous, or unfamiliar) as the within-subject factor. We found no significant main effect of the level of face familiarity, $F<1$ between the proportions of correct responses. This result indicates that participants accurately found target faces in the crowd of distractor faces in all three conditions.

\subsection{Reaction Time}

Mean reaction times for correct responses to target in each experimental condition are given in Figure 2. In order to reduce outlier effects (more than three standard deviations above the mean value for the condition), responses above three seconds ( $1.1 \%$ of all correct responses) were excluded from the analyses. A one-way repeated-measures ANOVA of the reaction times for correct responses was carried out to determine the effect of face familiarity. We found a significant main effect of the level of face familiarity on reaction time, $F(2,22)=$ $4.48, p<.05$. Post-hoc comparisons using Ryan's procedure $(\alpha=.05)$ revealed that reaction times in the unfamiliar face condition (1686 ms) were longer than those in the personally familiar face (1394 ms) or famous face (1418 ms) conditions $(p<.05)$, although there was no significant difference of reaction times between the personally familiar face and the famous face conditions. These results suggest that the visual search for unfamiliar faces is slower than that for personally familiar faces or famous faces.

\subsection{Eye Movements}

We recorded the participants' eye movement during the visual search task. In order to examine the difference in the visual search strategies used to recognize familiar faces versus unfamiliar faces, we focused on the proportions of those using a self-terminating search or an exhaustive search for the visual target. In this experiment, the

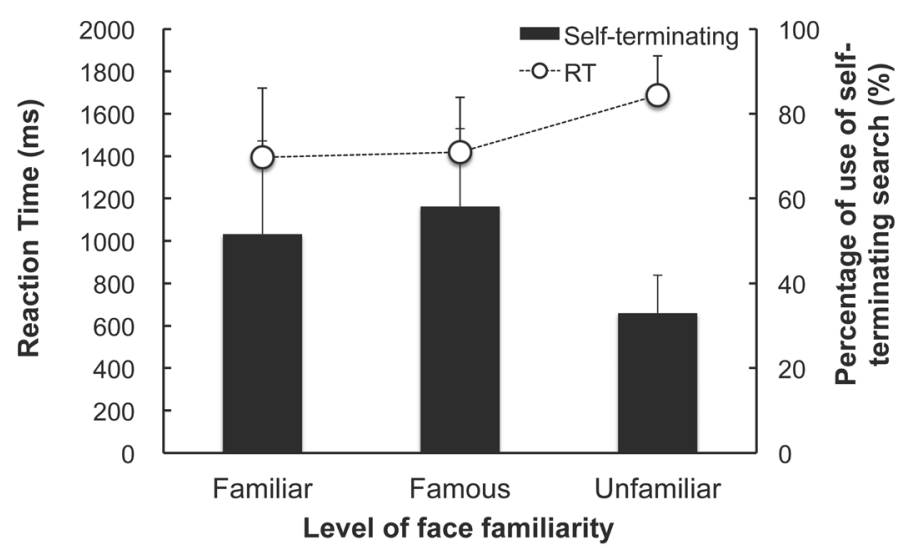

Figure 2. Mean reaction times (ms) for correct target searching and mean percentage of use of a self-terminating search in the personally familiar face, the famous face, and the unfamiliar face conditions. The open circles indicate the reaction times, and the solid bars indicate the percentages of use of the selfterminating search. Error bars represent standard error of the mean. 
self-terminating search was defined as the search strategy in which participants stop searching without seeing all four faces presented in a trial, and the exhaustive search was defined as the search strategy in which the participants see all the faces. Based on eye fixations that defined the intervals between the end of one saccade and the beginning of the next, we examined whether these fixations landed on the areas of interest that spanned from the top of the head to the bottom of the chin of each of the four faces presented in each trial.

Figure 2 also shows the average proportion of participants who used the self-terminating search in each experimental condition. A one-way repeated-measures ANOVA of the percentage of participants using the self-terminating search was carried out to determine the effect of face familiarity (personally familiar, famous, or unfamiliar). We found a significant main effect of the level of face familiarity, $F(2,22)=5.48, p<.05$. Post-hoc comparisons using Ryan's procedure $(\alpha=.05)$ revealed that the percentages of self-terminating search used in the unfamiliar face condition (33\%) were lower than those used in the personally familiar face (52\%) and famous face $(58 \%)$ conditions $(p<.05)$, although there was no significant difference in percentage of self-terminating search used between the personally familiar face and the famous face conditions. These results suggest that use of the self-terminating search in the unfamiliar face condition occurred less frequently than in the personally familiar face and famous face conditions, and that the exhaustive search is more common than the selfterminating search in the unfamiliar face condition.

\section{Discussion}

The purpose of the present study was to investigate whether the visual search process for familiar faces differs from that for unfamiliar faces. In order to address this issue, the experiment was conducted by using a singletarget visual search task for each face condition while recording eye movements during the task. We employed three different levels of face familiarity: personally familiar faces, famous faces, or unfamiliar faces. The mean reaction times demonstrate that the visual search for unfamiliar faces is slower than that for personally familiar faces and famous faces, but there is no significant difference in the time taken to recognize personally familiar and famous faces. Eye movements during the visual search task showed that the exhaustive search occurred more frequently than the self-terminating search when participants searched through arrays of personally familiar faces for a unfamiliar target face, but both personally familiar face and famous face target searches did not show more frequent use of the exhaustive search.

Our findings illuminate the mechanisms underlying the visual search for familiar and unfamiliar faces in terms of search facilitation and strategy. The reaction time results suggest that both the real world experiences with faces (i.e., personally familiar faces) and experience through the media (i.e., famous faces) facilitate the processing of facial identification in a crowd. These results are consistent with previous studies that have shown advantages in recognizing familiar faces over unfamiliar faces (e.g., Balas et al., 2007; Clutterbuck \& Johnston, 2002; Young et al., 1985). Visual components of rich internal features (e.g., eyes and mouth) and semantic longterm memory components (e.g., biographical information, name, and personal traits) of familiar faces allow for faster recognition than unfamiliar faces. Although it is not clear whether the face processing advantages observed in the personally familiar and famous faces arise from the same basic mechanism or from separate ones, a variety of mechanisms could cause fast processing of familiar faces. One possibility is that the internal features of often-viewed faces induce faster focusing on particular features of a target face (e.g., the shape of the eyes) (Balas et al., 2007; Young et al., 1985) or on configural information about the spatial relationships between the internal features of the face (Johnston \& Edmonds, 2009). Another possibility is that a strong facial memory provides a low threshold to be able to make a decision about a familiar face target. The prior observation of those faces would function as a visual priming effect. However, the present study cannot distinguish between these possibilities.

Interestingly, the exhaustive search for a target face occurred more frequently than the self-terminating search in the unfamiliar face condition, but this was not true in both the personally familiar face and the famous face conditions. These results imply that people do an exhaustive search of the entire array before they indicate the position of an unfamiliar face. Previous studies have suggested that there is a longer reaction time involved in the recognition of unfamiliar faces (e.g., Balas et al., 2007; Clutterbuck \& Johnston, 2002; Young et al., 1985) and a longer duration of scanning of unfamiliar faces before the formation of a perceptual decision (Barton et al., 2006). However, in a visual search for unfamiliar faces, our results suggest that a longer reaction time for unfamiliar face recognition in a crowd results not only from the longer duration of scanning a target unfamiliar face, 
but also from the exhaustive search of the entire array. A plausible interpretation of this scanning pattern is that participants compare an unfamiliar face (target) with familiar faces (distractors) if the unfamiliar face itself is not enough to make a correct decision. Thus, the participants defer a decision on an unfamiliar target face until the scanning for familiar faces is over. In terms of limitations, the relatively small sample size $(n=12)$ in the current study means that our results should be interpreted with caution.

In conclusion, our study demonstrates that the visual search process for familiar faces (i.e., personally familiar and famous) differs from that for unfamiliar faces. Our results indicate that an exhaustive search of entire arrays occurred more frequently than a self-terminating search when participants searched through arrays of personally familiar faces for an unfamiliar face, but this was not true for both personally familiar faces and famous faces searches.

\section{Authorship}

Ito and Sakurai developed the study concept. Both authors contributed to the study design. Testing and data collection were performed by Ito and Sakurai, and Ito and Sakurai performed the data analysis and interpretation. Ito wrote the paper. All authors approved the final version of the paper for submission.

\section{References}

Allison, T., Puce, A., \& McCarthy, G. (2000). Social Perception from Visual Cues: Role of the STS Region. Trends in Cognitive Sciences, 4, 267-276. http://dx.doi.org/10.1016/S1364-6613(00)01501-1

Balas, B., Cox, D., \& Conwell, E. (2007). The Effect of Real-World Personal Familiarity on the Speed of Face Information Processing. PLoS ONE, 2, Article ID: e1223. http://dx.doi.org/10.1371/journal.pone.0001223

Barton, J. J. S., Radcliffe, N., Cherkasova, M. V., Edelman, J., \& Intriligator, J. M. (2006). Information Processing during Face Recognition: The Effects of Familiarity, Inversion, and Morphing on Scanning Fixations. Perception, 35, $1089-1105$. http://dx.doi.org/10.1068/p5547

Becker, D. V., Anderson, U. S., Mortensen, C. R., Neufeld, S. L., \& Neel, R. (2011). The Face in the Crowd Effect Unconfounded: Happy Faces, Not Angry Faces, Are More Efficiently Detected in Single- and Multiple-Target Visual Search Tasks. Journal of Experimental Psychology: General, 140, 637-659. http://dx.doi.org/10.1037/a0024060

Bruce, V. (1979). Searching for Politicians: An Information Processing Approach to Face Recognition. Quarterly Journal of Experimental Psychology, 31, 373-395. http://dx.doi.org/10.1080/14640747908400734

Bruce, V. (1982). Changing Faces: Visual and Non-Visual Coding Processes in Face Recognition. British Journal of Psychology, 73, 105-116. http://dx.doi.org/10.1111/j.2044-8295.1982.tb01795.X

Bruce, V., Henderson, Z., Greenwood, K., Hancock, P. J. B., Burton, A. M., \& Miller, P. (1999). Verification of Face Identities from Images Captured on Video. Journal of Experimental Psychology: Applied, 5, 339-360. http://dx.doi.org/10.1037/1076-898X.5.4.339

Burton, A. M., Bruce, V., \& Hancock, P. J. B. (1999). From Pixels to People: A Model of Familiar Face Recognition. Cognitive Science, 23, 1-31. http://dx.doi.org/10.1207/s15516709cog2301_1

Clutterbuck, R., \& Johnston, R. A. (2002). Exploring Levels of Face Familiarity by Using an Indirect Face-Matching Measure. Perception, 31, 985-994. http://dx.doi.org/10.1068/p3335

Ellis, H. D., Shepherd, J. W., \& Davies, G. M. (1979). Identification of Familiar and Unfamiliar Faces from Internal and External Features; Some Implications for Theories of Face Recognition. Perception, 8, 431-439. http://dx.doi.org/10.1068/p080431

Ewbank, M. P., \& Andrews, T. J. (2008). Differential Sensitivity for Viewpoint between Familiar and Unfamiliar Faces in Human Visual Cortex. NeuroImage, 40, 1857-1870. http://dx.doi.org/10.1006/nimg.1998.0409

Gobbini, M. I., \& Haxby, J. V. (2007). Neural Systems for Recognition of Familiar Faces. Neuropsychologia, 45, 32-41. http://dx.doi.org/10.1016/j.neuropsychologia.2006.04.015

Gobbini, M. I., Leibenluft, E., Santiago, N., \& Haxby, J. V. (2004). Social and Emotional Attachment in the Neural Representation of Faces. NeuroImage, 22, 1628-1635. http://dx.doi.org/10.1016/j.neuroimage.2004.03.049

Gorno-Tempini, M. L., \& Price, C. J. (2001). Identification of Famous Faces and Buildings: A Functional Neuroimaging Study of Semantically Unique Items. Brain, 124, 2087-2097. http://dx.doi.org/10.1093/brain/124.10.2087

Halgren, E., Dale, A. M., Sereno, M. I., Tootell, R. B. H., Marinkovic, K., \& Rosen, B. R. (1999). Location of Human FaceSelective Cortex with Respect to Retinotopic Areas. Human Brain Mapping, 7, 29-37.

Haxby, J. V., Hoffman, E. A., \& Gobbini, M. I. (2000). The Distributed Human Neural System for Face Perception. Trends 
in Cognitive Sciences, 4, 223-233. http://dx.doi.org/10.1016/S1364-6613(00)01482-0

Hill, H., \& Bruce, V. (1996). Effects of Lighting on the Perception of Facial Surfaces. Journal of Experimental Psychology: Human Perception and Performance, 22, 986-1004. http://dx.doi.org/10.1037/0096-1523.22.4.986

Hill, H., Schyns, P. G., \& Akamatsu, S. (1997). Information and Viewpoint Dependence in Face Recognition. Cognition, 62, 201-222. http://dx.doi.org/10.1016/S0010-0277(96)00785-8

Hoffman, E. A., \& Haxby, J. V. (2000). Distinct Representations of Eye Gaze and Identity in the Distributed Human Neural System for Face Perception. Nature Neuroscience, 3, 80-84. http://dx.doi.org/10.1038/71152

Johnston, A., Hill, H., \& Carman, N. (1992). Recognizing Faces: Effects of Lighting Direction, Inversion, and Brightness Reversal. Perception, 21, 365-375. http://dx.doi.org/10.1068/p210365

Johnston, R., \& Edmonds, A. (2009). Familiar and Unfamiliar Face Recognition: A Review. Memory, 17, 577-596. http://dx.doi.org/10.1080/09658210902976969

Kanwisher, N., McDermott, J., \& Chun, M. M. (1997). The Fusiform Face Area: A Module in Human Extrastriate Cortex Specialized for Face Perception. Journal of Neuroscience, 17, 4302-4311.

Malone, D. R., Morris, H. H., Kay, M. C., \& Levin, H. S. (1982). Prosopagnosia: A Double Dissociation between the Recognition of Familiar and Unfamiliar Faces. Journal of Neurology, Neurosurgery \& Psychiatry, 45, 820-822. http://dx.doi.org/10.1136/jnnp.45.9.820

Natu, V., \& O’Toole, A. J. (2011). The Neural Processing of Familiar and Unfamiliar Faces: A Review and Synopsis. British Journal of Psychology, 102, 726-747. http://dx.doi.org/10.1111/j.2044-8295.2011.02053.x

O’Donnell, C., \& Bruce, V. (2001). Familiarisation with Faces Selectively Enhances Sensitivity to Changes Made to the Eyes. Perception, 30, 755-754. http://dx.doi.org/10.1068/p3027

O’Toole, A. J., Edelman, S., \& Bülthoff, H. H. (1998). Stimulus-Specific Effects in Face Recognition over Changes in Viewpoint. Vision Research, 38, 2351-2363. http://dx.doi.org/10.1016/S0042-6989(98)00042-X

O’Toole, A. J., Weimer, S., Dunlop, J., Barwick, R., Ayyad, J., \& Phillips, P. J. (2010). Recognizing People from Dynamic Video: Dissecting Identity with a Fusion Approach. Vision Research, 10, 643. http://dx.doi.org/10.1167/10.7.643

Persike, M., Meinhardt-Injac, B., \& Meinhardt, G. (2013). The Preview Benefit for Familiar and Unfamiliar Faces. Vision Research, 87, 1-9. http://dx.doi.org/10.1016/j.visres.2013.05.005

Rossion, B., Schiltz, C., \& Crommelinck, M. (2003). The Functionally Defined Right Occipital and Fusiform "Face Areas" Discriminate from Visually Familiar Faces. NeuroImage, 19, 877-883. http://dx.doi.org/10.1016/S1053-8119(03)00105-8

Sugiura, M., Kawashima, R., Nakamura, K., Sato, N., Nakamura, A., Kato, T., \& Fukuda, H. (2001). Activation Reduction in Anterior Temporal Cortices during Repeated Recognition of Faces of Personal Acquaintances. NeuroImage, 13, 877890. http://dx.doi.org/10.1006/nimg.2001.0747

Thornton, T. L., \& Gilden, D. L. (2007). Parallel and Serial Processes in Visual Search. Psychological Review, 114, 71-103. http://dx.doi.org/10.1037/0033-295X.114.1.71

Tranel, D., Damasio, A. R., \& Damasio, H. (1988). Intact Recognition of Facial Expression, Sex, and Age in Patients with Impaired Recognition of Facial Identity. Neurology, 28, 690-696. http://dx.doi.org/10.1212/WNL.38.5.690

Treisman, A. M., \& Gelade, G. (1980). A Feature-Integration Theory of Attention. Cognitive Psychology, 12, 97-136. http://dx.doi.org/10.1016/0010-0285(80)90005-5

Walton, B. R. P., \& Hills, P. J. (2012). Face Distortion Aftereffects in Personally Familiar, Famous, and Unfamiliar Faces. Frontiers in Psychology, 3, Article ID: 258. http://dx.doi.org/10.3389/fpsyg.2012.00258

Warrington, E. K., \& James, M. (1967). An Experimental Investigation of Facial Recognition in Patients with Unilateral Cerebral Lesions. Cortex, 3, 317-326. http://dx.doi.org/10.1016/S0010-9452(67)80020-0

Wolfe, J. M. (1992). The Parallel Guidance of Visual Attention. Current Directions in Psychological Science, 1, $124-128$. http://dx.doi.org/10.1111/1467-8721.ep10769733

Young, A. W., Hay, D. C., McWeeny, K. H., Flude, B. M., \& Ellis, A. W. (1985). Matching Familiar and Unfamiliar Faces on Internal and External Features. Perception, 14, 737-746. http://dx.doi.org/10.1068/p140737

Young, A. W., Newcombe, F., DeHaan, E. H. F., Small, M., \& Hay, D. C. (1993). Face Perception after Brain Injury. Selective Impairments Affecting Identity and Expression. Brain, 116, 941-959. http://dx.doi.org/10.1093/brain/116.4.941 
Scientific Research Publishing (SCIRP) is one of the largest Open Access journal publishers. It is currently publishing more than 200 open access, online, peer-reviewed journals covering a wide range of academic disciplines. SCIRP serves the worldwide academic communities and contributes to the progress and application of science with its publication.

Other selected journals from SCIRP are listed as below. Submit your manuscript to us via either submit@scirp.org or Online Submission Portal.
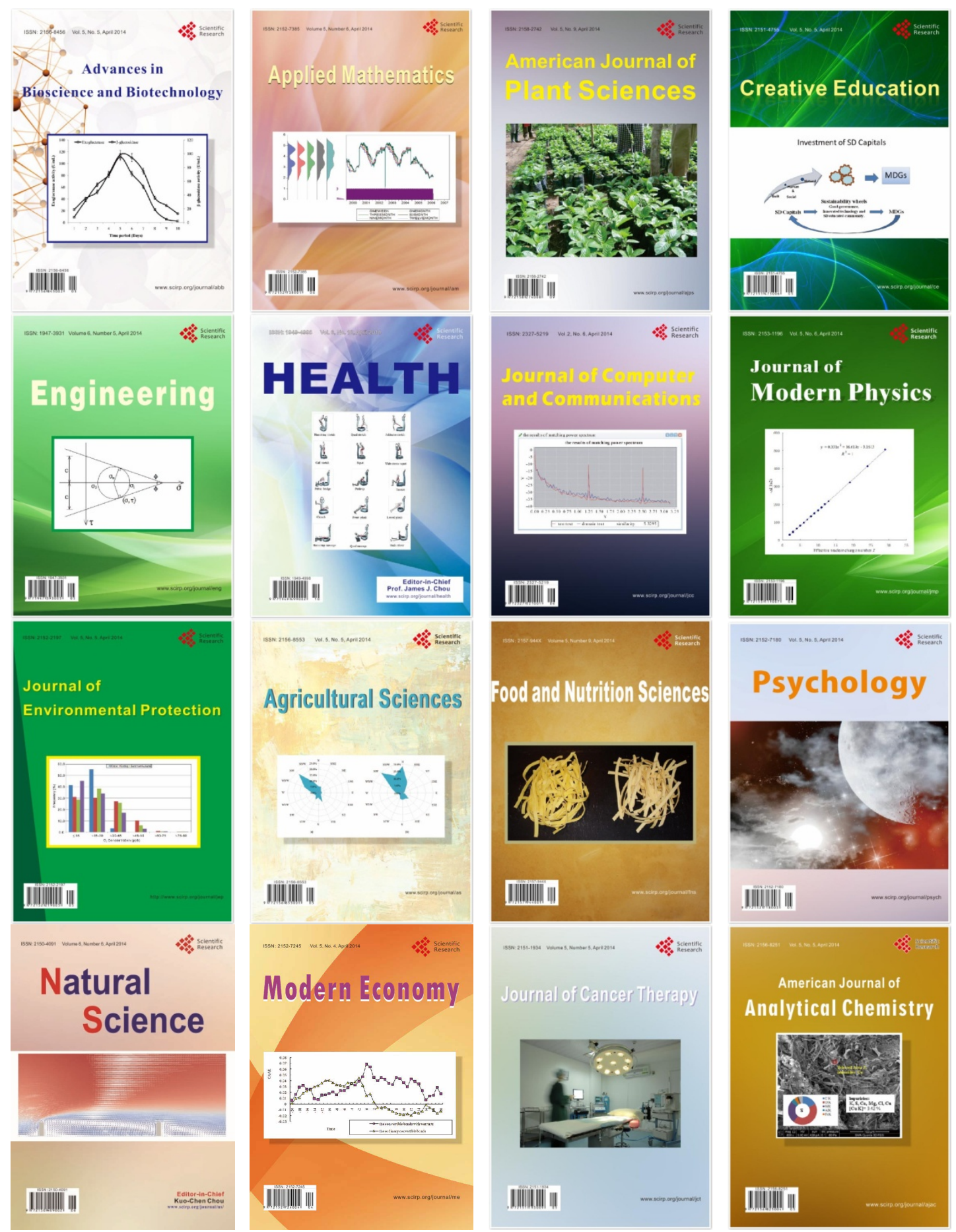